\title{
Association between mild cognitive impairment and dementia and undernutrition among elderly people in Central Africa: some results from the EPIDEMCA (Epidemiology of Dementia in Central Africa) programme
}

Sophie Pilleron ${ }^{1,2}$, Pierre Jésus ${ }^{1,2,3}$, Jean-Claude Desport ${ }^{1,2,3 *}$, Pascal Mbelesso ${ }^{4}$, Bébène

Ndamba-Bandzouzi $^{5}$, Jean-Pierre Clément ${ }^{6}$, Jean-François Dartigues ${ }^{7}$, Pierre-Marie Preux ${ }^{1,2,8}$ and Maëlenn Guerchet ${ }^{1,2,9}$ and the EPIDEMCA group (Maëlenn Guerchet, Bébène Ndamba-Bandzouzi, Pascal Mbelesso, Sophie Pilleron, Iléana Désormais, Philippe Lacroix, Victor Aboyans, Jean-Claude Desport, Pierre Jésus, Achille Tchalla, Benoît Marin, Jean-Pierre Clément, Jean-Charles Lambert, Jean-François Dartigues and Pierre-Marie Preux)

${ }^{1}$ INSERM, U1094, Tropical Neuroepidemiology, Limoges, France

${ }^{2}$ Univ. Limoges, UMR_S 1094, Tropical Neuroepidemiology, Institute of Neuroepidemiology and Tropical Neurology, CNRS FR 3503 GEIST, F-87000 Limoges, France

${ }^{3}$ CHU Limoges, Department of Nutrition, F-87000 Limoges, France

${ }^{4}$ Department of Neurology, Amitié Hospital, Bangui, Central African Republic

${ }^{5}$ Department of Neurology, CHU Brazzaville, Brazzaville, Republic of Congo

${ }^{6}$ Hospital and University Federation of Adult and Geriatric Psychiatry, Limoges, France

${ }^{7}$ INSERM U897, Bordeaux University, Bordeaux, France

${ }^{8}$ Centre of Epidemiology, Biostatistic, and Research Methodology, CEBIMER, CHU Limoges, Limoges, France

${ }^{9}$ Centre for Global Mental Health, Health Service and Population Research Department, Institute of Psychiatry, Psychology and Neuroscience, King's College London, London, UK

(Submitted 6 May 2014 - Final revision received 17 April 2015-Accepted 20 April 2015 - First published online 23 June 2015)

\section{Abstract}

Several studies in Western countries have shown an association between cognitive disorders and low BMI or weight loss in elderly people. However, few data are available in Africa. We analysed the association between cognitive disorders and undernutrition among elderly people in Central Africa. A cross-sectional, multicentre, population-based study using a two-phase design was carried out in subjects aged 65 years and above in the Central African Republic (CAR) and the Republic of Congo (ROC). All subjects were interviewed using the Community Screening Interview for Dementia, and those with low performance were clinically assessed by a neurologist and underwent further psychometrical tests. Diagnostic and Statistical Manual-IV and Petersen's criteria were required for the diagnoses of dementia and mild cognitive impairment (MCI), respectively. Undernutrition was evaluated using mid-upper arm circumference (MUAC) $<24 \mathrm{~cm}$, BMI $<18.5 \mathrm{~kg} / \mathrm{m}^{2}$ and arm muscular circumference (AMC) $<5$ th percentile. Multivariate binary logistic regression models were used to estimate the associations. In CAR, MCI was associated with MUAC $<24 \mathrm{~cm}$ (OR $0.7,95 \%$ CI $0.4,1 \cdot 0)$ and dementia with BMI $<18.5 \mathrm{~kg} / \mathrm{m}^{2}$ (OR 2.3, $95 \%$ CI 1·6, 3.1), AMC < 5 th percentile (OR 2.3, 95\% CI 1.1, 4.6) and MUAC <24 cm (OR 1.8, 95\% CI 1.4, 2.4). In ROC, both MCI and dementia were associated with all markers of undernutrition, but only AMC < 5th percentile was significantly associated with MCI (OR 3.1, $95 \%$ CI 1.9, 4.8). In conclusion, cognitive disorders were associated with undernutrition. However, further studies are needed to elucidate the relationship between MCI and undernutrition in CAR.

Key words: Undernutrition: Mild cognitive impairment: Dementia: Africa: Older adults

Dementia affected 44.4 million people worldwide in 2013 , a figure expected to rise to 135.5 million by $2050^{(1)}$. African countries are not spared by this phenomenon ${ }^{(1)}$; however, the literature on dementia is still sparse. Neurodegenerative dementia is preceded by a period of cognitive decline often termed mild cognitive impairment (MCI). Elderly individuals

Abbreviations: AMC, arm muscular circumference; CAR, Central African Republic; CSI-D, Community Screening Interview for Dementia; EPIDEMCA, Epidemiology of Dementia in Central Africa; MCI, mild cognitive impairment; MUAC, mid-upper arm circumference; ROC, Republic of Congo. 
with MCI constitute a high-risk population for developing dementia $^{(2)}$.

In Western industrialised countries, weight loss ${ }^{(3,4)}$ and low late-life $\mathrm{BMI}^{(5-7)}$ have been associated with increased risk of dementia. Weight loss started before the onset of dementia ${ }^{(8)}$ and continued thereafter ${ }^{(9)}$. Several mechanisms that differ depending on the progress of the disease could explain the weight loss ${ }^{(10)}$. In the early stages, weight loss may be related to a hypermetabolic state and/or an increase in physical activity linked to abnormal motor behaviour, a tendency to agitation and aggression ${ }^{(10)}$. At more advanced stages, weight loss could be linked to a reduction in food intake due to forgetting to eat, decreased appetite subsequent to brain dementia-related changes, the presence of concomitant chronic diseases or depression ${ }^{(10)}$. Weight loss in older people affects both lean and fat mass ${ }^{(11)}$. Loss of lean mass (but not fat mass) emerges in the early stages of dementia ${ }^{(12)}$, while fat mass has been associated with more severe stages of dementia ${ }^{(13)}$.

In low- and middle-income countries, studies on the relationship between nutritional status and cognitive disorders are scarce. A multicentre, cross-sectional study conducted in seven countries (China, Cuba, Mexico, Venezuela, Peru, Dominican Republic and India) has reported that undernutrition, defined by mid-upper arm circumference (MUAC) below $21 \mathrm{~cm}$, had been associated with a higher probability of dementia among people aged 65 years and older and its prevalence increased with dementia severity ${ }^{(14)}$. In the same population, Taylor and colleagues ${ }^{(15)}$ showed that dementia and its severity were associated with both lower MUAC, used as proxy of lean mass, and lower waist circumference as a marker of fat mass. Albanese et al. ${ }^{(16)}$ showed that dementia severity had been independently associated with reported weight loss in older adults and the association strengthened through the stages of dementia. In a case-control study carried out in Chinese people aged 55 years or above, a decrease in BMI and waist circumference has been associated with amnesic MCI and Alzheimer's disease ${ }^{(17)}$.

In Africa, a multicentre study conducted in Central Africa ${ }^{(18)}$ and a study in Nigeria ${ }^{(19)}$ have observed that a BMI $<18.5 \mathrm{~kg} / \mathrm{m}^{2}$ has been positively associated with dementia in older adults. A longitudinal study in Nigeria has found that BMI decline has been associated with incident MCI and dementia in older people followed up over 10 years ${ }^{(20)}$.

Most studies used BMI as an anthropometric indicator of nutritional status. However, its interpretation in older people requires caution due to the decrease in height with age and because BMI cannot distinguish between different body compartments. MUAC and arm muscular circumference (AMC) are anthropometric indicators used as proxies of lean mass ${ }^{(15,21)}$. A MUAC $<24 \mathrm{~cm}$ and an AMC $<5$ th percentile of reference population are also used to define undernutrition ${ }^{(22)}$.

We therefore hypothesised that cognitive disorders are associated with undernutrition. The objective of the present study was to evaluate the association between MCI and dementia and undernutrition in elderly people in the Central African Republic (CAR) and Republic of Congo (ROC) in Central Africa.

\section{Materials and methods}

\section{Ethics statement}

Approvals were obtained from the Ethics Committee of the Ministry of Public Health in CAR, the CERSSA (Comité d' Ethique de la Recherche en Sciences de Santé) in ROC, and the Comité de Protection des Personnes du Sud-Ouest et d'Outre-Mer 4 in France. All the participants and/or their families gave informed consent before being included in the study.

\section{Study population}

The present study population consisted of participants in the Epidemiology of Dementia in Central Africa (EPIDEMCA) programme - a multicentre, community-based, cross-sectional study conducted in rural and urban areas in CAR and ROC between November 2011 and December 2012. The detailed methodology is published elsewhere in an open-access publication $^{(23)}$. In brief, subjects aged 65 years and above who had lived in the study area for at least 6 months were eligible. The study areas consisted of the capitals of CAR (Bangui) and ROC (Brazzaville), and two rural regions (Nola in CAR and Gamboma in ROC). The sample size was calculated a priori with the aim of estimating dementia prevalence, and was then estimated at 500 in each study site. In urban areas, the selection was carried out using random sampling proportional to the main city subdivision size. In rural areas, exhaustive sampling using a door-to-door approach was preferred due to logistic and financial constraints.

\section{Measures}

Data were collected in two phases. The first phase was conducted in the general population at participants' homes. Interviews were carried out by ten specifically trained interviewers who were students in medical school (at least in their 6th year of curriculum), students of biology or nurses from Bangui and Brazzaville Universities using a questionnaire including cognitive, physical, demographic and risk factor assessment. Neurologists conducted the second phase in participants with probable cognitive disorders at the closest hospital or health centre between 3 and 14 weeks later.

\section{Anthropometric measurements}

Weight, height, knee height, MUAC and triceps skinfold thickness were measured during the first phase in every consenting participant. The detailed methodology is presented in Table 1.

\section{Mild cognitive impairment and dementia diagnoses}

During the first phase, cognitive testing was performed using the Community Screening Interview for Dementia (CSI-D) ${ }^{(24)}$ adapted, back-translated and pretested in local languages (Sango in CAR; Lari, Lingala and Kituba in ROC). A relative of each old person included was interviewed at the same time using the CSI-D informant section to assess daily activities. 
Table 1. Anthropometric measurement and undernutrition markers

\begin{tabular}{|c|c|c|c|c|c|}
\hline Marker & Proxy & Measurement & Precision & Formula & Threshold \\
\hline BMI & Total fat mass & $\begin{array}{l}\text { The weight was measured on } \\
\text { mechanical scales } \\
\text { The height was measured using a } \\
\text { carpenter metre along a surface } \\
\text { as flat as possible, such as door } \\
\text { or wall } \\
\text { If the height could not be } \\
\text { measured, it was evaluated using } \\
\text { the knee height measured to the } \\
\text { nearest centimetre on the right } \\
\text { side with subjects in spine pos- } \\
\text { ition with the Chumlea's formula } \\
\text { for non-Hispanic Black people }{ }^{(49)}\end{array}$ & $\begin{array}{l}\text { Weight: } 100 \mathrm{~g} \\
\text { Height: } 1 \mathrm{~cm}\end{array}$ & $\begin{array}{l}\text { BMl }\left(\mathrm{kg} / \mathrm{m}^{2}\right)=\text { weight }(\mathrm{kg}) / \\
(\text { height }(\mathrm{m}))^{2} \\
\text { Men: height }(\mathrm{cm})=79.69+ \\
\quad(1.85 \times \text { knee height }(\mathrm{cm})) \\
-(0.14 \times \text { age }(\text { year })) \\
\text { Women: height }(\mathrm{cm}) \\
=89.58+(1.61 \times \\
\text { knee height }(\mathrm{cm}))-(0.17 \times \text { age } \\
\text { (year) })\end{array}$ & Below $18.5 \mathrm{~kg} / \mathrm{m}^{2}$ \\
\hline MUAC & Lean mass & $\begin{array}{l}\text { Measured on the right arm with a } \\
\text { non-stretch tape at a level } \\
\text { midway between acromion and } \\
\text { olecranon }\end{array}$ & $1 \mathrm{~mm}$ & - & Below $24 \mathrm{~cm}$ \\
\hline AMC & Lean mass & $\begin{array}{l}\text { The triceps skinfold thickness (TST) } \\
\text { was measured three times on the } \\
\text { right arm according to Lohman } \\
\text { standard procedures }{ }^{(50)} \text { with an } \\
\text { Harpenden caliper. The average } \\
\text { of the three measures was used } \\
\text { in the calculation }\end{array}$ & $0.2 \mathrm{~mm}$ & $\begin{array}{l}\mathrm{AMC}(\mathrm{cm})=\operatorname{MUAC}(\mathrm{cm})- \\
\pi \text { TST }(\mathrm{cm})\end{array}$ & Below 5th percentile \\
\hline
\end{tabular}

MUAC, mid-upper arm circumference; AMC, arm muscular circumference.

Every subject with a poor performance in the CSI-D cognitive tests (cognitive score $\leq 24.5$; sensitivity $=93 \%$ and specificity $=82 \%$ in a previous study, personal data) was suspected to have cognitive impairment and invited for further clinical assessment with a neurologist (phase 2).

Further psychometric tests were conducted, including the Free and Cued Selective Reminding Test ${ }^{(25)}$, Zazzo's cancellation task ${ }^{(26)}$ and Isaac's Set Test of verbal fluency ${ }^{(27)}$. Neurologists performed examinations during which histories of stroke and depressive disorders were sought. Orientation skills and daily activities were also investigated in order to evaluate the level of dependence. They diagnosed dementia and MCI according to the Diagnostic and Statistical ManualIV criteria $^{(28)}$ and MCI Petersen criteria ${ }^{(29)}$, respectively. In case of uncertain cases, an experienced neurologist reviewed all medical records and test performances in order to reach a consensus.

\section{Covariates}

All covariates were collected during the first phase. Sociodemographic data included age, sex (male/female), marital status (living as a couple/living alone, including widow, single and separated), formal education (yes/no), country (CAR/ROC) and area (urban/rural). Age was ascertained by official documents, from an informant or through a local event calendar. Two historical landmarks were also used in each country according to the validated method of age estimation using historical events ${ }^{(30,31)}$. Health-related covariates included frailty (defined as Study of Osteoporotic Fractures (SOF) index $>2^{(32)}$ ) and history of stroke (yes/no). Lifestyle covariates included smoking status (current non-smoker (including former smoker); current smoker), physical activity (defined as having walked or cycled at least $150 \mathrm{~min}$ the past week and categorised by yes/no) ${ }^{(33)}$ and excessive alcohol consumption (defined as having consumed at least 21 alcohol units for males and 14 alcohol units for females the past week). Depressive and anxiety symptoms were assessed with the Geriatric Mental State version $\mathrm{B} 3^{(34)}$. Dietary factors included difficulties in eating an individual's fill (yes/no) and the daily frequency of consumption of dairy products, fruits, vegetables, legumes, starches, oleaginous food, meat/fish/egg and sweet food. Psychosocial factors consisted of death of spouse (yes/no) and death of a child, these two events occurring after the participant reached 65 years of age (yes/no).

\section{Data management and analysis}

All data collected were computerised directly during the interview using an interface specially created with Epidata version 3.1 (EpiData Association). Undernutrition was assessed using three different markers used as dependent variables: BMI $<18.5 \mathrm{~kg} / \mathrm{m}^{2(22)}$, MUAC $<24 \mathrm{~cm}^{(22)}$ and AMC $<5$ th sexspecific percentile based on Frisancho chart for the age of 65-74.9 years ${ }^{(35)}$. Cognitive disorders, used as independent variables consisted of three categories: cognitively normal, MCI and dementia. All covariates were used as categorical variables, except for age, which was used as a continuous variable since linearity hypothesis could not be rejected.

Sample characteristics described by country of residence included age, area, sex, marital status, education level, health-related factors, lifestyle factors, psychological factors, dietary factors, psychosocial factors, cognitive disorders, anthropometric measures (weight, height, BMI, MUAC and AMC) and markers of undernutrition. Means with their standard deviation were used as summary statistics for age and 
continuous anthropometric measures. Percentages were calculated for all categorical variables. Characteristics were compared between countries using $\chi^{2}$ test for categorical variables or $t$ test and ANOVA for continuous variables.

The prevalence of undernutrition as defined by each of the three markers was calculated according to cognitive disorders for each country.

To test the relationship between cognitive disorders and undernutrition, we used binary logistic regression models using a complete case analysis method. We started with unadjusted binary logistic regression model (model 0 ). The sociodemographic variables were entered first (model 1), then health-related covariates (model 2), lifestyle covariates (model 3), psychological covariates (model 4), dietary covariates (model 5) and finally psychosocial covariates (model 6). In the final models, we tested for interaction between cognitive disorders and sex, country of residence and area (rural/urban) using overall Wald $\chi^{2}$ test with a level of significance fixed at 0.05. Significant interaction was found between cognitive disorders and country of residence when AMC was considered as dependent variable. All results were thus presented stratified by country. Because of the lack of validated thresholds to define undernutrition in older African people, we modelled the effects of cognitive disorders on BMI, MUAC and AMC as continuous variable separately for each country using linear regression adjusted for sociodemographic, health-related, lifestyle, psychological, dietary and psychosocial covariates. In each model, a potential cluster effect of districts due to the study design was taken into account and entered into the model. The statistical analysis was carried out using Stata version 10.1 for Windows (StataCorp).

\section{Results}

\section{Sample characteristics}

In total, 2002 participants were included. The prevalence of dementia was $8.4 \%$ in CAR and $6.9 \%$ in ROC and the prevalence of MCI was $7 \cdot 2$ and $6 \cdot 1 \%$, respectively (details on the prevalence of dementia are the purpose of another specific paper). Table 2 presents a comparison of the prevalence of undernutrition as defined by the three markers used in addition to other characteristics between CAR and ROC. Only undernutrition defined as BMI $<18.5 \mathrm{~kg} / \mathrm{m}^{2}$ was significantly different between the countries, with a lower prevalence in $\operatorname{ROC}(P=0.002)$.

Fig. 1 shows the prevalence of undernutrition according to cognitive disorders. Among MCI subjects, the prevalence of undernutrition ranged from 10.0 to $30.5 \%$ in CAR and from 32.0 to $42.0 \%$ in ROC, according to the marker considered. Among demented subjects, the figures varied from $30 \cdot 8$ to $65.6 \%$ in CAR and from 28.9 to $52.3 \%$ in ROC.

\section{Association between cognitive disorders and undernutrition}

Separate binary logistic regression models were used to test the association between cognitive disorders and undernutrition on a sample with no missing values for any undernutrition markers ( $n 1847$ subjects; Table 3). In CAR, MCI was only associated with a lower probability of having MUAC $<24 \mathrm{~cm}$ in unadjusted and adjusted models. However, dementia was associated with a higher probability of being undernourished as defined by the three markers in unadjusted models but significantly with BMI $<18.5 \mathrm{~kg} / \mathrm{m}^{2}$ and MUAC $<24 \mathrm{~cm}$. Adjustment for sociodemographic covariates reduced the strength of the associations between dementia and undernutrition defined by BMI $<18.5 \mathrm{~kg} / \mathrm{m}^{2}$ and MUAC $<24 \mathrm{~cm}$; however, subsequent adjustments did not have notable effects on the relationships. While it did not reach significance in the unadjusted model, the association between dementia and AMC $<5$ th percentile was significant after adjustment for sociodemographic covariates and in subsequent models. In ROC, in unadjusted and fully adjusted models, all OR suggested an increased probability of undernutrition in individuals with MCI or dementia; however, the associations became nonsignificant after several adjustments. Only the association between AMC < $<$ th percentile and MCI remained highly significant in fully adjusted models.

\section{Sensitivity analysis}

Because of a lack of validated thresholds to define undernutrition in older African people, we examined the relationship of BMI, MUAC and AMC as continuous dependent variables with cognitive disorders in separate linear regression models (Table 4). In CAR, MCI was associated with none of the indicators; however, dementia was associated with all of them with coefficients indicating a lower mean in demented participants than normal ones. In ROC, $\beta$-coefficients indicated a lower BMI, MUAC and AMC mean in both MCI and demented subjects.

\section{Discussion}

The present study investigated the association between cognitive disorders (MCI and dementia) and undernutrition in a general elderly population from Central Africa, a subject very poorly documented in African countries so far ${ }^{(18-20,36)}$. The present study confirms our hypothesis that cognitive disorders are associated with undernutrition in this older population even if all the associations did not reach statistical significance.

In ROC, MCI was associated with a higher probability of being undernourished as defined by $\mathrm{AMC}<5$ th percentile. The same tendency was observed for other markers of undernutrition even if they were not statistically significant. In our sensitivity analysis, MCI was also associated with lower BMI, MUAC and AMC. However, in CAR, no association was observed. In the literature, few studies have investigated the relationship between MCI and weight loss, low BMI or undernutrition $^{(17,36,37)}$, and the majority were conducted in clinical settings. All showed a deterioration in nutritional status in MCI subjects compared with those cognitively unimpaired. In addition, several longitudinal studies have shown that low BMI had been associated with preclinical stages of Alzheimer's disease ${ }^{(38,39)}$. The present results observed in a general older 
Table 2. Characteristics of study population according to their residence country, EPIDEMCA (Epidemiology of Dementia in Central Africa), 2011-12

(Number of participants; percentages; mean values and standard deviations)

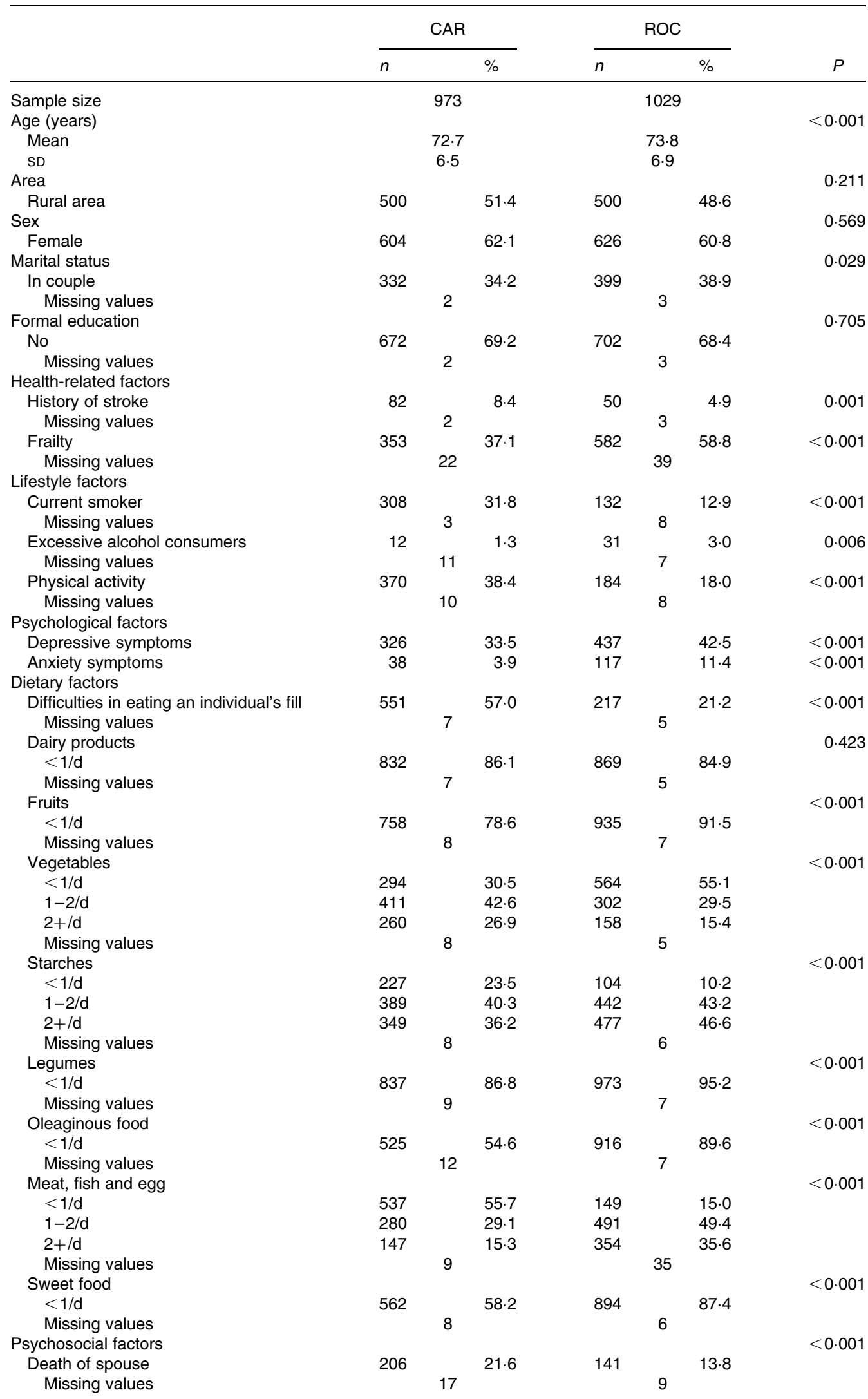


Table 2. Continued

\begin{tabular}{|c|c|c|c|c|c|}
\hline & \multicolumn{2}{|c|}{ CAR } & \multicolumn{2}{|c|}{ ROC } & \multirow[b]{2}{*}{$P$} \\
\hline & $n$ & $\%$ & $n$ & $\%$ & \\
\hline Death of a child & 428 & $44 \cdot 9$ & 336 & $32 \cdot 9$ & $<0.001$ \\
\hline Missing values & \multicolumn{2}{|c|}{19} & \multicolumn{2}{|c|}{9} & \\
\hline Death of a relative & 587 & 61.4 & 708 & 69.5 & $<0.001$ \\
\hline Missing values & \multicolumn{2}{|c|}{17} & \multicolumn{2}{|c|}{10} & \\
\hline Cognitive disorders & & & & & 0.307 \\
\hline Normal & 726 & 84.4 & 794 & $87 \cdot 0$ & \\
\hline $\mathrm{MCl}$ & 62 & $7 \cdot 2$ & 56 & $6 \cdot 1$ & \\
\hline Dementia & 72 & 8.4 & 63 & 6.9 & \\
\hline Missing values & \multicolumn{2}{|c|}{113} & \multicolumn{2}{|c|}{116} & \\
\hline \multicolumn{6}{|l|}{ Anthropometric measures } \\
\hline Weight (kg) & & & & & 0.344 \\
\hline Mean & \multicolumn{2}{|c|}{$51 \cdot 8$} & \multicolumn{2}{|c|}{52.4} & \\
\hline SD & \multicolumn{2}{|c|}{$13 \cdot 0$} & \multicolumn{2}{|c|}{$14 \cdot 0$} & \\
\hline Missing values & \multicolumn{2}{|c|}{41} & \multicolumn{2}{|c|}{53} & \\
\hline Height $(\mathrm{cm})$ & \multirow{2}{*}{\multicolumn{2}{|c|}{$159 \cdot 0$}} & \multirow{2}{*}{\multicolumn{2}{|c|}{155.9}} & $<0.001$ \\
\hline Mean & & & & & \\
\hline SD & \multicolumn{2}{|c|}{$9 \cdot 0$} & \multicolumn{2}{|c|}{$9 \cdot 0$} & \\
\hline Missing values & \multicolumn{2}{|c|}{19} & \multicolumn{2}{|c|}{45} & \\
\hline BMI $\left(\mathrm{kg} / \mathrm{m}^{2}\right)$ & & & & & $<0.001$ \\
\hline Mean & \multicolumn{2}{|c|}{$20 \cdot 4$} & \multicolumn{2}{|c|}{21.5} & \\
\hline SD & \multicolumn{2}{|c|}{4.4} & \multicolumn{2}{|c|}{$5 \cdot 1$} & \\
\hline Missing values & \multicolumn{2}{|c|}{45} & & & \\
\hline $\operatorname{MUAC}(\mathrm{cm})$ & & & & & 0.01 \\
\hline Mean & & & & & \\
\hline SD & & & & & \\
\hline Missing values & & & & & \\
\hline $\mathrm{AMC}(\mathrm{cm})$ & & & & & 0.314 \\
\hline Mean & & & & & \\
\hline SD & & & & & \\
\hline Missing values & & & & & \\
\hline Markers of undernutrition & & & & & \\
\hline $\mathrm{BMI}<18.5 \mathrm{~kg} / \mathrm{m}^{2}$ & 355 & $38 \cdot 3$ & 290 & $30 \cdot 2$ & $<0.001$ \\
\hline Missing values & & & & & \\
\hline $\mathrm{MUAC}<24 \mathrm{~cm}$ & 251 & $26 \cdot 6$ & 234 & $24 \cdot 0$ & 0.188 \\
\hline Missing values & & & & & \\
\hline AMC $<5$ th percentile & 194 & 20.9 & 195 & $20 \cdot 4$ & 0.795 \\
\hline Missing values & & & & & \\
\hline
\end{tabular}

CAR, Central African Republic; ROC, Republic of Congo; $\mathrm{MCl}$, mild cognitive impairment; MUAC, mid-upper arm circumference; AMC, arm muscular circumference.

population from ROC were thus consistent with the literature. In CAR, the lack of difference in the prevalence of undernutrition between normal and MCI subjects explaining the lack of association observed is unclear. It is unlikely that this could be explained by difference in MCI assessment between countries since (1) the same expert (J.-F. D.) trained neurologists from both countries and (2) this expert reviewed each record. Future longitudinal studies are needed to confirm or refute this specific finding.
Dementia was associated with a higher probability of being undernourished whatever the marker used in both countries, even after adjustment for several confounders. These results are consistent with other studies conducted in African countries ${ }^{(18-20)}$ and other low- and middle-income countries $^{(14-16)}$, but also with several large longitudinal studies conducted in Western countries ${ }^{(40-42)}$.

A stronger association with AMC was observed in ROC. This suggests that undernutrition is preferentially linked to muscle
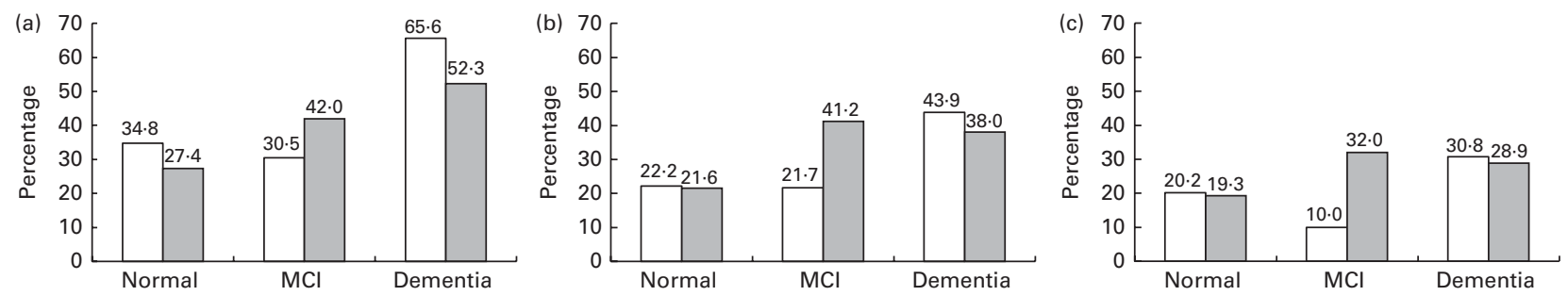

Fig. 1. The prevalence of undernutrition according to cognitive disorders in Central African Republic ( $\square$ ) and Republic of Congo ( $\square$ ), EPIDEMCA (Epidemiology of Dementia in Central Africa), 2011-12. (a) BMI $<18.5 \mathrm{~kg} / \mathrm{m}^{2}$, (b) mid-upper arm circumference $<24 \mathrm{~cm}$, (c) arm muscular circumference $<5$ th percentile. MCl, mild cognitive impairment. 
Table 3. Unadjusted and adjusted OR from separate binary logistic regression measuring the association between cognitive disorders and undernutrition, EPIDEMCA (Epidemiology of Dementia in Central Africa), $2011-12$

(Odds ratios and $95 \%$ confidence intervals)

\begin{tabular}{|c|c|c|c|c|c|c|c|c|c|c|c|c|c|c|c|c|c|c|}
\hline & \multicolumn{9}{|c|}{ CAR } & \multicolumn{9}{|c|}{ ROC } \\
\hline & \multicolumn{3}{|c|}{$\mathrm{BMI}<18.5 \mathrm{~kg} / \mathrm{m}^{2}$} & \multicolumn{3}{|c|}{ AMC $<5$ th percentile } & \multicolumn{3}{|c|}{ MUAC $<24 \mathrm{~cm}$} & \multicolumn{3}{|c|}{$\mathrm{BMI}<18.5 \mathrm{~kg} / \mathrm{m}^{2}$} & \multicolumn{3}{|c|}{ AMC $<5$ th percentile } & \multicolumn{3}{|c|}{ MUAC $<24 \mathrm{~cm}$} \\
\hline & OR & $95 \% \mathrm{Cl}$ & $P$ & OR & $95 \% \mathrm{Cl}$ & $P$ & OR & $95 \% \mathrm{Cl}$ & $P$ & OR & $95 \% \mathrm{Cl}$ & $P$ & OR & $95 \% \mathrm{Cl}$ & $P$ & OR & $95 \% \mathrm{Cl}$ & $P$ \\
\hline Model $0^{\star}(n)$ & & & & & 808 & & & & & & & & & 838 & & & & \\
\hline Normal & 1 & & $<0.001$ & 1 & & 0.025 & 1 & & $<0.001$ & 1 & & $<0.001$ & 1 & & $<0.001$ & 1 & & $<0.001$ \\
\hline $\mathrm{MCl}$ & 0.8 & $0.4,1.7$ & 0.585 & 0.5 & $0.3,0.8$ & 0.005 & 0.9 & $0.6,1.4$ & 0.670 & $2 \cdot 0$ & $1 \cdot 1,3.5$ & 0.026 & 1.9 & $1 \cdot 2,2 \cdot 9$ & 0.008 & $2 \cdot 6$ & $1 \cdot 6,4.0$ & 0.001 \\
\hline Dementia & 3.3 & $2 \cdot 4,4.6$ & $<0.001$ & 1.5 & $0 \cdot 8,2 \cdot 8$ & 0.193 & $2 \cdot 8$ & $2 \cdot 0,3 \cdot 8$ & $<0.001$ & 2.9 & $2 \cdot 0,4 \cdot 2$ & $<0.001$ & 1.9 & $1.3,2.9$ & 0.006 & 2.5 & $1.7,3.8$ & 0.001 \\
\hline Model 1† $(n)$ & & & & & 807 & & & & & & & & & 837 & & & & \\
\hline Normal & 1 & & $<0.001$ & 1 & & 0.003 & 1 & & 0.001 & 1 & & 0.017 & 1 & & $<0.001$ & 1 & & $<0.001$ \\
\hline $\mathrm{MCl}$ & 0.8 & $0.3,1 \cdot 8$ & 0.523 & 0.7 & $0.3,1.5$ & 0.371 & 0.7 & $0.5,1 \cdot 1$ & 0.165 & 1.6 & $1 \cdot 0,2 \cdot 7$ & 0.065 & 2.9 & $2 \cdot 0,4 \cdot 2$ & $<0.001$ & 1.9 & $1 \cdot 1,3 \cdot 3$ & 0.029 \\
\hline Dementia & $2 \cdot 8$ & $2 \cdot 1,3 \cdot 9$ & $<0.001$ & $2 \cdot 4$ & $1.4,4.1$ & 0.004 & 1.9 & $1 \cdot 4,2 \cdot 6$ & 0.001 & $2 \cdot 3$ & $1 \cdot 2,4.5$ & 0.020 & $2 \cdot 5$ & $1 \cdot 3,4.9$ & 0.012 & $1 \cdot 8$ & $1 \cdot 1,2 \cdot 7$ & 0.015 \\
\hline Model 2‡ (n) & & & & & 798 & & & & & & & & & 816 & & & & \\
\hline Normal & 1 & & $<0.001$ & 1 & & 0.011 & 1 & & 0.003 & 1 & & 0.022 & 1 & & $<0.001$ & 1 & & $<0.001$ \\
\hline $\mathrm{MCl}$ & 0.7 & $0 \cdot 3,1 \cdot 7$ & 0.450 & 0.6 & $0.3,1.5$ & 0.242 & 0.7 & $0.5,1.1$ & 0.104 & $1 \cdot 6$ & $0.9,2.6$ & 0.075 & $2 \cdot 8$ & $1 \cdot 9,4 \cdot 1$ & $<0.001$ & 1.9 & $1 \cdot 2,3 \cdot 1$ & 0.016 \\
\hline Dementia & 2.5 & $1 \cdot 8,3 \cdot 3$ & $<0.001$ & 1.9 & $1 \cdot 0,3 \cdot 4$ & 0.044 & 1.6 & $1 \cdot 2,2 \cdot 2$ & 0.002 & $2 \cdot 4$ & $1 \cdot 2,4 \cdot 8$ & 0.022 & $2 \cdot 4$ & $1.2,4.9$ & 0.023 & 1.8 & $1 \cdot 1,3.0$ & 0.033 \\
\hline Model $3 \S(n)$ & & & & & 787 & & & & & & & & & 812 & & & & \\
\hline Normal & 1 & & $<0.001$ & 1 & & 0.010 & 1 & & 0.003 & 1 & & 0.078 & 1 & & $<0.001$ & 1 & & $<0.001$ \\
\hline $\mathrm{MCl}$ & 0.7 & $0.3,1 \cdot 7$ & 0.449 & 0.6 & $0.3,1.4$ & 0.210 & 0.7 & $0.5,1.0$ & 0.071 & 1.4 & $0.9,2.4$ & 0.147 & $2 \cdot 7$ & $1 \cdot 9,4 \cdot 0$ & $<0.001$ & 1.8 & $1.1,2.9$ & 0.023 \\
\hline Dementia & 2.5 & $1.9,3.4$ & $<0.001$ & 1.9 & $1 \cdot 1,3 \cdot 4$ & 0.033 & 1.7 & $1 \cdot 3,2 \cdot 3$ & 0.002 & $2 \cdot 2$ & $1 \cdot 1,4.4$ & 0.030 & $2 \cdot 6$ & $1.1,5.9$ & 0.027 & 1.8 & $1 \cdot 0,3 \cdot 3$ & 0.048 \\
\hline Model $4 \|(n)$ & & & & & 787 & & & & & & & & & 812 & & & & \\
\hline Normal & 1 & & $<0.001$ & 1 & & 0.006 & 1 & & 0.002 & 1 & & 0.089 & 1 & & $<0.001$ & 1 & & 0.002 \\
\hline $\mathrm{MCl}$ & 0.7 & $0.3,1 \cdot 7$ & 0.435 & 0.6 & $0.2,1.5$ & 0.238 & 0.7 & $0.5,1.1$ & 0.098 & 1.5 & $0.9,2.5$ & 0.130 & 3.0 & $2 \cdot 1,4 \cdot 4$ & $<0.001$ & 1.7 & $1 \cdot 0,2 \cdot 9$ & 0.043 \\
\hline Dementia & $2 \cdot 6$ & $1 \cdot 8,3 \cdot 7$ & $<0.001$ & 1.9 & $1 \cdot 1,3.5$ & 0.036 & 1.7 & $1 \cdot 3,2 \cdot 3$ & 0.002 & $2 \cdot 3$ & $1.1,4.9$ & 0.035 & $2 \cdot 8$ & $1 \cdot 2,6 \cdot 2$ & 0.019 & 1.8 & $1 \cdot 0,3 \cdot 3$ & 0.055 \\
\hline Model 59 $(n)$ & & & & & 778 & & & & & & & & & 786 & & & & \\
\hline Normal & 1 & & $<0.001$ & 1 & & 0.004 & 1 & & $<0.001$ & 1 & & 0.213 & 1 & & 0.002 & 1 & & 0.007 \\
\hline $\mathrm{MCl}$ & 0.7 & $0.3,1 \cdot 7$ & 0.371 & 0.6 & $0.3,1.3$ & 0.160 & 0.7 & $0.5,1.0$ & 0.031 & 1.5 & $0.8,2.9$ & 0.175 & 3.1 & $2 \cdot 0,4 \cdot 8$ & $<0.001$ & 1.6 & $0.9,2 \cdot 7$ & 0.077 \\
\hline Dementia & $2 \cdot 2$ & $1 \cdot 6,3 \cdot 0$ & $<0.001$ & 1.9 & $1.0,3.8$ & 0.057 & 1.7 & $1 \cdot 3,2 \cdot 1$ & $<0.001$ & $2 \cdot 1$ & $0.8,5.3$ & 0.097 & 2.5 & $0.9,7 \cdot 1$ & 0.087 & 1.7 & $0.8,3.3$ & 0.133 \\
\hline Model $6^{\star \star}(n)$ & & & & & 769 & & & & & & & & & 784 & & & & \\
\hline Normal & 1 & & $<0.001$ & 1 & & 0.002 & 1 & & $<0.001$ & 1 & & 0.213 & 1 & & 0.002 & 1 & & 0.011 \\
\hline $\mathrm{MCl}$ & 0.7 & $0.3,1 \cdot 7$ & 0.357 & 0.6 & $0.3,1 \cdot 3$ & 0.156 & 0.7 & $0.4,1.0$ & 0.033 & 1.5 & $0.8,2.9$ & 0.204 & $3 \cdot 1$ & $1 \cdot 9,4 \cdot 8$ & $<0.001$ & 1.6 & $0.9,2.7$ & 0.090 \\
\hline Dementia & $2 \cdot 3$ & $1 \cdot 6,3 \cdot 1$ & $<0.001$ & $2 \cdot 3$ & $1 \cdot 1,4 \cdot 6$ & 0.030 & 1.8 & $1 \cdot 4,2 \cdot 4$ & $<0.001$ & $2 \cdot 2$ & $0.9,5.8$ & 0.090 & $2 \cdot 6$ & $0.8,9.0$ & 0.108 & 1.8 & $0.9,3 \cdot 7$ & 0.112 \\
\hline
\end{tabular}


Table 4. $\beta$-Coefficients from separate multivariate linear regression* measuring the association between cognitive disorders and BMI, mid-upper arm circumference (MUAC) and arm muscular circumference (AMC), EPIDEMCA (Epidemiology of Dementia in Central Africa), 2011-12 ( $\beta$-Coefficients and $95 \%$ confidence intervals)

\begin{tabular}{|c|c|c|c|c|c|c|c|c|c|}
\hline & \multicolumn{3}{|c|}{ BMI } & \multicolumn{3}{|c|}{ MUAC } & \multicolumn{3}{|c|}{ AMC } \\
\hline & $\beta$ & $95 \% \mathrm{Cl}$ & $P$ & $\beta$ & $95 \% \mathrm{Cl}$ & $P$ & $\beta$ & $95 \% \mathrm{Cl}$ & $P$ \\
\hline \multicolumn{10}{|l|}{ CAR $(n 769)$} \\
\hline Normal & 1 & & 0.003 & 1 & & 0.001 & 1 & & 0.004 \\
\hline $\mathrm{MCl}$ & 0.52 & $-0.90,1.94$ & 0.441 & 0.07 & $-0.67,0.81$ & 0.847 & 0.03 & $-0.64,0.70$ & 0.922 \\
\hline Dementia & $-1 \cdot 19$ & $-1.91,-0.47$ & 0.003 & -1.38 & $-2 \cdot 16,-0.61$ & 0.002 & $-1 \cdot 10$ & $-1.84,-0.36$ & 0.007 \\
\hline \multicolumn{10}{|l|}{ ROC ( $n 784)$} \\
\hline Normal & 1 & & 0.001 & 1 & & 0.004 & 1 & & 0.002 \\
\hline $\mathrm{MCl}$ & -1.47 & $-2 \cdot 10,-0.83$ & 0.001 & -1.40 & $-2.28,-0.53$ & 0.005 & -1.48 & $-2.04,-0.91$ & $<0.001$ \\
\hline Dementia & $-1 \cdot 67$ & $-3.30,-0.03$ & 0.047 & -1.81 & $-3.68,0.07$ & 0.057 & -0.95 & $-2.69,0.79$ & 0.248 \\
\hline
\end{tabular}

CAR, Central African Republic; MCl, mild cognitive impairment; ROC, Republic of Congo.

${ }^{*}$ Adjusted for age, sex, formal education, marital status and area, frailty, stroke, excessive alcohol consumption, current smoking, physical activity, depressive and anxious symptoms, difficulties in eating an individual's fill, frequency of consumption of dairy products, fruits, vegetables, legumes, starches, oleaginous food, meat/fish/egg and sweet food, death of spouse occurred after the participant reached the age of 65 years and death of a child after the participant reached the age of 65 years.

loss even in the early stages of the disease. MUAC and BMI do not distinguish between lean and fat masses, while AMC specially assesses the muscle mass, main lean mass component. This is consistent with the results of Burns et al. ${ }^{(12)}$ who found that reduced lean mass was associated with early stage Alzheimer's disease. However, this contradicts the findings of Abellan et al. ${ }^{(13)}$ who did not find an association between sarcopenia and cognitive impairment in women aged 75 years or above and Wirth et al. ${ }^{(43)}$ who found no association between mild or moderate cognitive impairment and fat-free mass.

There are no thresholds to define undernutrition with BMI, MUAC or AMC in the older African population. We therefore chose those recommended by the WHO in adults $^{(22)}$. However, body composition changes with age, lean body mass decreases while fat mass increases ${ }^{(44)}$. We cannot be sure about the validity of these thresholds in our older population. The use of indicators as quantitative variables in our sensitivity analysis enabled us to overcome the use of cut-offs to define undernutrition. Participants with cognitive impairment had a worse nutritional status than did others even if they were not undernourished as defined by the markers used in the present study. Deterioration of nutritional status seems to affect all body compartments since fat and muscular mass assessed by BMI and AMC, respectively, are both associated with cognitive disorders. This confirms previous results ${ }^{(12,13)}$.

The present study has several other limitations. Due to its cross-sectional design, it is not possible to determine the temporality of the observed associations. Several literature reviews have suggested that weight loss, which could lead to undernutrition, would be more a consequence than a cause of dementia $^{(10,45,46)}$. However, we cannot exclude that undernutrition be linked to others mechanisms. Some potential confounders were not taken into account such as social factors or other comorbidities. In addition, mechanisms of weight loss in dementia are still unknown. We then cannot exclude a reverse causality since some results have shown that higher adiposity at old age would protect against cognitive disorders $^{(41)}$. The low number of prevalent cases of MCI and dementia by country may affect the precision of estimates and lead to non-significant associations. This fact has also precluded the analysis of the effect of the severity of dementia, which was associated with weight loss in several studies ${ }^{(15,16)}$. It has also precluded the analysis of the relationship with dementia subtypes. However, previous studies have failed to show the differences in nutritional status according to dementia subtypes ${ }^{(37,47)}$. Among the total EPIDEMCA sample, the BMI value was not available for $5.6 \%$ of subjects, the value of MUAC for $4.1 \%$ and the value of AMC for $5.7 \%$. However, subjects without anthropometric measurements were older than those with measurements, but also more frail as defined by the SOF index ${ }^{(32)}$ and had more cognitive impairment (data not shown). This may have led to underestimation of the observed associations. In addition, we cannot exclude the possibility that the most undernourished people would die before presenting cognitive disorders, leading to a survival bias that underestimated the observed associations. We cannot ensure that we did not miss cases during the first phase since we did not make ascertainment of participants screened negative with CSI-D. However, the threshold used was established from the same population in a previous study ${ }^{(18)}$ with a good sensitivity and specificity; therefore, we believed that this number would be very low.

The strengths of the present study are the large sample size and the mix of participants coming from rural and urban areas of two African countries. To our knowledge, this is the first study of this magnitude conducted in French-speaking African countries. Another strength is the richness of the anthropometric measures available and the accuracy with which they have been used.

In terms of public health, the present results highlight the need for weight monitoring in demented people and more generally in elderly people, as their population will substantially grow during the next decades. Unfortunately, the older people are not a priority in the health and nutrition programmes of countries in sub-Saharan Africa, which primarily target children ( $<5$ years), women (pregnant and breast-feeding) and people living with HIV/AIDS ${ }^{(48)}$. Primary care health 
workers are not yet trained to manage with older adults who often present several comorbidities. However, monitoring and controlling weight loss in older adults may potentially increase longevity, promote compression of morbidity, hence improving the quality of life of patients and indirectly carers ${ }^{(15)}$.

\section{Conclusion}

The present results in Central Africa are consistent with an increased probability of undernutrition in cognitively impaired older subjects. Data from the present study add to existing information on the relationship between cognitive disorders and undernutrition and show the same trends as in Western and other low- and middle-income countries. However, longitudinal studies on larger samples seem to be necessary to elucidate this relationship in a context where lifestyle and culture are different from those of wealthier countries.

\section{Acknowledgements}

The authors would like to thank the participants in the EPIDEMCA study as well as all the students and nurses involved for their assistance. They also thank the town hall staff, mayors and chiefs of districts for their collaboration, and the Universities of Bangui (CAR) and Marien Ngouabi in Brazzaville (ROC), the Health ministries of the CAR and the ROC for their support.

The present study was funded by The French National Agency (Agence nationale de la recherché; ANR) through the ANR-09-MNPS-009-01 grant. The University of Limoges, Doctoral School 523 of Limoges University, the Limousin Regional Council and the French Ministry of Higher Education and Research funded the doctoral position of S. P.; The funding sources had no role in the design, implementation, analysis or interpretation of the data.

The authors' contributions are as follows: S. P., M. G., B. N.-B. and P. M. supervised the data collection; J.-F. D., B. N.-B. and P. M. were responsible for diagnosing cognitive disorders; S. P. conducted the data analysis and wrote the first draft; M. G. and J.-P. C. were involved in the data analysis and in the interpretation of the data. All authors reviewed the manuscript, provided further contributions and suggestions and approved the final draft. All authors worked collectively to design the EPIDEMCA protocol.

None of the authors has any conflict of interest to declare.

\section{References}

1. Prince M, Guerchet M \& Prina M (2013) Policy Brief for Heads of Government: The Global Impact of Dementia 2013-2050. London: Alzheimer's Disease International. http://www.alz.co.uk/research/GlobalImpactDementia2013. pdf

2. Petersen RC, Doody R, Kurz A, et al. (2001) Current concepts in mild cognitive impairment. Arch Neurol $\mathbf{5 8}$ 1985-1992.

3. Renvall MJ, Spindler AA, Nichols JF, et al. (1993) Body composition of patients with Alzheimer's disease. J Am Diet Assoc 93, $47-52$
4. Berlinger WG \& Potter JF (1991) Low body mass index in demented outpatients. J Am Geriatr Soc 39, 973-978.

5. Fitzpatrick AL, Kuller LH, Lopez OL, et al. (2009) Midlife and late-life obesity and the risk of dementia: cardiovascular health study. Arch Neurol 66, 336-342.

6. Luchsinger JA \& Gustafson DR (2009) Adiposity and Alzheimer's disease. Curr Opin Clin Nutr Metab Care 12, 15-21.

7. Luchsinger JA, Patel B, Tang M-X, et al. (2007) Measures of adiposity and dementia risk in elderly persons. Arch Neurol 64, 392-398.

8. Knopman DS, Edland SD, Cha RH, et al. (2007) Incident dementia in women is preceded by weight loss by at least a decade. Neurology 69, 739-746.

9. Soto ME, Secher M, Gillette-Guyonnet S, et al. (2012) Weight loss and rapid cognitive decline in community-dwelling patients with Alzheimer's disease. J Alzheimers Dis 28, 647-654.

10. Sergi G, De Rui M, Coin A, et al. (2013) Weight loss and Alzheimer's disease: temporal and aetiologic connections. Proc Nutr Soc 72, 160-165.

11. Baumgartner RN, Heymsfield SB \& Roche AF (1995) Human body composition and the epidemiology of chronic disease. Obes Res 3, 73-95.

12. Burns JM, Johnson DK, Watts A, et al. (2010) Reduced lean mass in early Alzheimer disease and its association with brain atrophy. Arch Neurol 67, 428-433.

13. Abellan van Kan G, Cesari M \& Gillette-Guyonnet S (2013) Sarcopenia and cognitive impairment in elderly women: results from the EPIDOS cohort. Age Ageing 42, 196-202.

14. Prince M, Acosta D, Ferri CP, et al. (2011) The association between common physical impairments and dementia in low and middle income countries, and, among people with dementia, their association with cognitive function and disability. A 10/66 Dementia Research Group population-based study. Int J Geriatr Psychiatry 26, 511-519.

15. Taylor CL, Albanese E \& Stewart R (2012) The association of dementia with upper arm and waist circumference in seven low- and middle-income countries: the 10/66 cross-sectional surveys. J Gerontol A Biol Sci Med Sci 67, 897-904.

16. Albanese E, Taylor C, Siervo M, et al. (2013) Dementia severity and weight loss: a comparison across eight cohorts. The 10/66 study. Alzheimers Dement J Alzheimers Assoc 9, 649-656.

17. Chu L-W, Tam S, Lee PWH, et al. (2009) Late-life body mass index and waist circumference in amnestic mild cognitive impairment and Alzheimer's disease. J Alzheimers Dis 17, 223-232.

18. Guerchet M, Mouanga AM, M'belesso P, et al. (2012) Factors associated with dementia among elderly people living in two cities in Central Africa: the EDAC multicenter study. J Alzheimers Dis 29, 15-24.

19. Ochayi B (2006) Risk factors for dementia in central Nigeria. Aging Ment Health 10, 616-620.

20. Ogunniyi A, Gao S, Unverzagt FW, et al. (2011) Weight loss and incident dementia in elderly Yoruba Nigerians: a 10-year follow-up study. Int Psychogeriatr 23, 387-394.

21. Gurney JM \& Jelliffe DB (1973) Arm anthropometry in nutritional assessment: nomogram for rapid calculation of muscle circumference and cross-sectional muscle and fat areas. Am J Clin Nutr 26, 912-915.

22. World Health Organization (1984) Physical Status: The Use and Interpretation of Anthropometry. Report of a WHO Expert Committee. Technical Report Series No. 854. Geneva: World Health Organization.

23. Guerchet M, Mbelesso P, Ndamba-Bandzouzi B, et al. (2014) Epidemiology of dementia in Central Africa (EPIDEMCA): 
protocol for a multicentre population-based study in rural and urban areas of the Central African Republic and the Republic of Congo. Springerplus 3, 338.

24. Hall K, Hendrie H, Brittain H, et al. (1993) The development of a dementia screening interview in two distinct languages. Int J Methods Psychiatr Res 3, 1-28.

25. Grober E, Buschke H, Crystal H, et al. (1988) Screening for dementia by memory testing. Neurology 38, 900-903.

26. Zazzo R (1974) Test des deux barrages (Zazzo's cancellation task). In Actualités Pédagogiques et Psychologiques, vol. 7, Neuchâtel, Switzerland: Delachaux \& Niestlé.

27. Isaacs B \& Kennie AT (1973) The Set test as an aid to the detection of dementia in old people. BrJ Psychiatry 123, 467-470.

28. American Psychiatric Association (2000) Diagnostic and Statistical Manual of Mental Disorders, 4th ed., text revised. Washington, DC: APA.

29. Petersen RC (2004) Mild cognitive impairment as a diagnostic entity. J Intern Med 256, 183-194.

30. Ogunniyi A \& Osuntokun BO (1993) Determination of ages of elderly Nigerians through historical events: validation of Ajayi-Igun 1963 listing. West Afr J Med 12, 189-190.

31. Paraïso MN, Houinato D, Guerchet M, et al. (2010) Validation of the use of historical events to estimate the age of subjects aged 65 years and over in Cotonou (Benin). Neuroepidemiology 35, 12-16.

32. Ensrud KE, Ewing SK, Taylor BC, et al. (2008) Comparison of 2 frailty indexes for prediction of falls, disability, fractures, and death in older women. Arch Intern Med 168, 382-389.

33. World Health Organization (2010) Global Recommendations on Physical Activity for Health. Geneva: WHO

34. Copeland JR, Dewey ME \& Griffiths-Jones HM (1986) A computerized psychiatric diagnostic system and case nomenclature for elderly subjects: GMS and AGECAT. Psychol Med 16, 89-99.

35. Frisancho AR (1981) New norms of upper limb fat and muscle areas for assessment of nutritional status. Am J Clin Nutr 34, 2540-2545.

36. Khater MS \& Abouelezz NF (2011) Nutritional status in older adults with mild cognitive impairment living in elderly homes in Cairo. Egypt J Nutr Health Aging 15, 104-108.

37. Orsitto G (2012) Different components of nutritional status in older inpatients with cognitive impairment. J Nutr Health Aging 16, 468-471.
38. Barrett-Connor E, Edelstein S, Corey-Bloom J, et al. (1998) Weight loss precedes dementia in community-dwelling older adults. J Nutr Health Aging 2, 113-114.

39. Johnson DK, Wilkins CH \& Morris JC (2006) Accelerated weight loss may precede diagnosis in Alzheimer disease. Arch Neurol 63, 1312-1317.

40. Gustafson DR, Bäckman K, Joas E, et al. (2012) 37 years of body mass index and dementia: observations from the prospective population study of women in Gothenburg. Sweden. J Alzheimers Dis 28, 163-171.

41. Hughes TF, Borenstein AR, Schofield E, et al. (2009) Association between late-life body mass index and dementia: the Kame Project. Neurology 72, 1741-1746.

42. Buchman AS, Wilson RS, Bienias JL, et al. (2005) Change in body mass index and risk of incident Alzheimer disease. Neurology 65, 892-897.

43. Wirth R, Bauer JM \& Sieber CC (2007) Cognitive function, body weight and body composition in geriatric patients. $Z$ Gerontol Geriatr 40, 13-20.

44. St-Onge M-P \& Gallagher D (2010) Body composition changes with aging: the cause or the result of alterations in metabolic rate and macronutrient oxidation? Nutrition 26 $152-155$

45. Inelmen EM, Sergi G, Coin A, et al. (2010) An openended question: Alzheimer's disease and involuntary weight loss: which comes first? Aging Clin Exp Res 22, 192-197.

46. Prince M, Albanese E, Guerchet M et al. (2014) Nutrition and Dementia. London: Alzheimer's Disease International. http://www.alz.co.uk/nutrition-report (February 2014)

47. Faxén-Irving G, Basun H \& Cederholm T (2005) Nutritional and cognitive relationships and long-term mortality in patients with various dementia disorders. Age Ageing 34, 136-141.

48. Kimokoti RW \& Hamer DH (2008) Nutrition, health, and aging in sub-Saharan Africa. Nutr Rev 66, 611-623.

49. Chumlea WC, Guo SS, Wholihan K, et al. (1998) Stature prediction equations for elderly non-Hispanic white, nonHispanic black, and Mexican-American persons developed from NHANES III data. J Am Diet Assoc 98, 137-142.

50. Lohman TG, Roche AF \& Martorell R (1988) Anthropometric Standardization Reference Manual. Champaign, IL: Human Kinetics Publishers. 